\title{
Cómo afrontar la adaptación cultural de las Multinacionales Chinas en España
}

\author{
Paloma Miravitlles-Matamoros ${ }^{1}$, Fariza Achcaoucaou, Felix Barahona-Márquez
}

Universitat de Barcelona, España

doi: $10.20420 /$ eni.2017.190

\begin{abstract}
Resumen
La adaptación cultural de las EMNEs en Europa, es de particular relevancia debido a la considerable distancia cultural entre economías emergentes y desarrolladas y los conflictos isomórficos que pueden surgir a nivel de filial. Aquí, examinamos este problema a través de dos casos de estudio de filiales chinas que operan en España. Nuestros hallazgos sugieren que la adopción y adaptación de los valores y prácticas culturales chinos al entorno local permite a la filial alinearse con la cultura de la empresa matriz al mismo tiempo que se integra en el entorno de acogida, resolviendo así cualquier conflicto isomórfico.
\end{abstract}

Palabras clave: multinacionales chinas, filiales, adaptación cultural, guanxi.

Clasificación JEL: M16, F23.

Fuente de referencia: Proyecto competitivo 'Multinacionales innovadoras en España (1950-2010). Creación y transferencia de conocimiento en la internacionalización de economías en desarrollo' (HAR2013-41453-P).

\section{Introducción y marco conceptual}

La proliferación de las multinacionales de mercados emergentes (EMNEs) es un fenómeno reciente que está captando cada vez mayor interés. Particularmente, las EMNEs de origen asiático son las corporaciones que más están creciendo intensificando su presencia internacional. Así, el número de multinacionales chinas en el ranking Global 500 de la revista Fortune ha pasado de 18 en 2005 (3,6\%), a 110 empresas en el 2016 (22\%). También en España la entrada de inversión directa extranjera (IED) de origen chino ha aumentado enormemente en los últimos años. Según datos del Registro Español de Inversión Extranjera, en 2008, la IED procedente de China y Hong Kong fue de 1,31 millones de euros, mientras que en 2015, la cifra pasó a ser de 1.699,26 millones euros, representando el 7,20\% sobre el total de la IED recibida en España.

Esta tendencia, que lejos de desaparecer parece que va a en aumento, plantea nuevos retos y cuestiones para estas corporaciones multinacionales. Así, según la Teoría Institucional (North, 1990; Scott, 1995), las EMNEs chinas sufren un gran choque cultural cuando se expanden hacia Europa. El entorno institucional chino se caracteriza por ser muy autoritario, centralizado y dominado por el gobierno (Hofstede, 2001), así como por la filosofía guanxi. El guanxi se asienta en un sistema ancestral de relaciones personales y conexiones sociales basada en el interés y el beneficio mutuo (Hwang, 1987; Kipnis, 1994, Wang, 2007), muy alejada de los valores culturales europeos. Básicamente el guanxi se compone de tres valores fundamentales: el renqing (similar a "deber un favor"), el ganqing (traducido como "sentimientos") y el xinren (parecido a la "confianza"), que gobiernan la manera de hacer negocios en China.

Debido al gran contraste cultural, las EMNEs chinas cuando instalan por primera vez una filial en Europa se enfrentan al llamado "conflicto isomórfico" (Forsgren, 2013). Este término se refiere a los problemas que sufre una filial

${ }^{1}$ Autor de correspondencia: paloma.miravitlles@ub.edu 
extranjera para responder a las presiones contrapuestas derivadas de dos entornos culturales distintos (el del país de origen de la EMNE y el del país de acogida). Por un lado, la filial tiene que encajar en la cultura local para ganar legitimidad externa y ser aceptada por los diferentes agentes del país de acogida. De hecho, es común que las EMNEs chinas entren en un país europeo adquiriendo una empresa local para superar así su desconocimiento sobre el país (Klossek, Linke, \& Nippa, 2012). Por otro lado, la filial adquirida también debe ganarse la legitimidad interna de la EMNE a la que ahora pertenece, adoptando sus valores culturales y prácticas para lograr un buen entendimiento en la corporación (Kostova, Kendall, \& Dacin, 2008). Conseguir el equilibrio supone un gran reto para los directivos de estas filiales chinas debido a la gran distancia institucional. Por ello, el presente artículo tiene como objetivo analizar, a partir de un estudio cualitativo, cómo se produce el ajuste cultural de las EMNEs chinas en un país europeo como España.

\section{Metodología}

Para abordar el objetivo de este artículo, se ha adoptado un estudio de caso, examinando la adaptación de dos empresas españolas adquiridas por dos grandes multinacionales chinas, como China Shipping Group y Sichuan Changhong. La tabla 1 muestra los casos seleccionados y los directivos entrevistados para conocer sus percepciones en cuanto a la su adaptación cultural.

\section{Distancia cultural percibida por las EMNES}

Una vez la EMNE china aterriza en Europa a través de la adquisición de una empresa local, el choque de culturas se deja sentir de manera inmediata. La cultura china contrasta con la española en diferentes aspectos; según el Director General de China Shipping: "No solo estamos hablando del problema del lenguaje como una limitación importante para la comunicación; los gestos, los modales y la comunicación no verbal también son realmente difíciles de entender... todo es nuevo para ambas partes".

Tabla 1. Casos de análisis

\begin{tabular}{|c|c|c|c|c|}
\hline EMNE & $\begin{array}{c}\text { Año } \\
\text { entrada } \\
\text { España }\end{array}$ & Actividad & Ciudad & Entrevistados \\
\hline $\begin{array}{c}\text { China } \\
\text { Shipping } \\
\text { Spain } \\
\text { Agency, } \\
\text { SL }^{2}\end{array}$ & 1999 & $\begin{array}{c}\text { Transporte } \\
\text { marítimo }\end{array}$ & Barcelona & $\begin{array}{c}\text { General } \\
\text { Manager }\end{array}$ \\
\hline $\begin{array}{c}\text { Huayi } \\
\text { Compressor } \\
\text { Barcelona, }\end{array}$ & 2013 & $\begin{array}{c}\text { Diseño, } \\
\text { de compresores } \\
\text { y unidades de } \\
\text { condensación } \\
\text { condura y } \\
\text { para el Mercado } \\
\text { de refrigeración }\end{array}$ & $\begin{array}{c}\text { Sant Quirze } \\
\text { del Vallés }\end{array}$ & $\begin{array}{c}\text { Human } \\
\text { Resource } \\
\text { Manager }\end{array}$ \\
\hline
\end{tabular}

Además de las barreras de comunicación, la distancia al poder y la fuerza de la jerarquía en las multinacionales chinas son un valor esencial. En la corporación Sichuan Changhong, las estructuras organizativas vertical y horizontal están claramente definidas y no se pueden transgredir bajo ninguna circunstancia. El director de Recursos Humanos de Huayi señala que "Es una cuestión de autoridad, nunca puedes desafiar una decisión que viene de arriba." Además a estos valores se le suma la abnegación de los trabajadores chinos para los cuales "el trabajo es más que trabajo, significa su vida y no hay fronteras entre ambas cosas". Según el directivo de Huayi, "Los gerentes chinos no entienden por qué los empleados españoles no quieren trabajar el fin de semana y por qué no consideran que trabajar horas extras sea un gran honor y una oportunidad para mostrar a los jefes lo duro que trabajan".

Otro valor cultural que causa fricciones es la elevada centralización de las decisiones en las EMNEs chinas, que es aún mayor cuando se trata ${ }^{2}$ Conservamos el nombre de esta empresa porque el caso fue analizado en 2015. Desde septiembre del 2016 esta filial fue integrada dentro de
Cosco Shipping Lines Spain, S.A. debido a la fusión de dos grandes chinas navieras: China Shipping y COSCO. 
de corporaciones controladas por el gobierno. Éste es el caso de las dos filiales examinadas, que cuentan con muy poco margen de maniobra. Así, el director de China Shipping comenta: "Recibimos una guía muy clara sobre cómo trabajar, cómo informar y cómo proceder. Solo tenemos cierta libertad de acción en los aspectos vinculados a las relaciones con las autoridades locales, los RRHH y los proveedores nacionales y las ventas".

Estas diferencias culturales dificultan enormemente la adaptación de los directivos chinos expatriados a la cultura europea. Aunque inicialmente tienen una buena predisposición, su cultura está tan arraigada que obstaculiza su integración en España y acentúa el conflicto isomórfico. En palabras del directivo de Huayi "Aunque los directivos chinos están abiertos a la adaptación, sus hábitos son tan diferentes y están tan bien establecidos que tienes que recordarles y explicarles una y otra vez [como se trabaja aquí]".

\section{Resolución del conflicto isomórfico}

Para solucionar los problemas de integración cultural, una medida común en las filiales de EMNEs chinas es utilizar comités de dirección mixtos. En el caso de Huayi, mientras que la dirección es mayoritariamente de origen chino, los directivos de $\mathrm{I}+\mathrm{D}$, Recursos Humanos y Ventas son españoles. En cambio, en China Shipping es al revés, la mayoría de directivos son españoles excepto por el Controller financiero y el Managing Director que son chinos. En esta filial los directivos españoles juegan un papel fundamental para ayudar a los directivos expatriados chinos a adaptarse, actuando como puente entre la cultura local y la de la matriz. Para asegurar la adaptación, los directivos locales tienen que esforzarse en entender la forma de pensar y actuar de los expatriados chinos y al mismo tiempo enseñarles qué comportamientos son adecuados en España y cuáles no. Pero además, tienen la responsabilidad de aprender sobre la cultura china y sensibilizar al resto de trabajadores de la filial en los valores de la corporación.

Una manera útil de aproximarse a la cultura china es adaptar el guanxi (Hwang, 1987; Kipnis, 1997) a la forma de trabajar española. En los dos casos analizados, los directivos locales adoptan el guanxi en sus relaciones para aumentar la legitimidad ante los expatriados y ganar el favor de la matriz, aunque adaptándolo a las prácticas locales. Las dos filiales implementan las tres componentes del guanxi (i.e., renqing, xinren y ganqing) en su intento de responder a las diferentes fuerzas institucionales para resolver el conflicto isomorfico.

Para los directivos chinos, la reprocidad y la empatía son esenciales para el éxito de las relaciones comerciales (Hwang, 1987) y se fundamentan en el continuo intercambio de favores entre los distintos agentes (renqing). Aunque estos dos principios son parte del lenguaje universal de hacer negocios, en China las redes personales de influencia basadas en los intercambios a largo plazo constituyen un principio básico que orienta la manera de hacer negocios en ese país. Como explican los directivos de las filiales entrevistadas, ellos han interiorizado y adaptado esta manera de proceder y hacer negocios en España. En el caso de China Shipping, "si tienes una buena relación comercial, es normal hacer favores, pero los chinos tienen una concepción más larga del tiempo debido a las creencias sociales del confucianismo. No tienen ninguna obligación de devolver el favor de inmediato, al contrario, pueden pasar años hasta que lo devuelvan".

Además, en la cultura china, el intercambio de favores va más allá del trabajo y los negocios, adoptando esta manera de actuar también en el plano personal. Aquí cobran especial relevancia las relaciones personales que se establecen entre los directivos chinos expatriados y los españoles que les ayudan a resolver sus problemas diarios y a construir amistades personales de confianza. 
La esencia de cualquier relación de negocio para un directivo chino se basa en las continuadas y repetidas muestras de confianza. Sólo pasado el tiempo y demostrados buenos resultados empresariales es posible ganar credibilidad (xinyong) y construir las necesarias bases de mutua confianza y seguridad (xinren) (Hwang, 1987; Kipnis, 1994). A este respecto, el director de China Shipping señala: "La confianza es un aspecto básico de las relaciones profesionales exitosas, pero para los chinos es mucho más grande que eso". En consecuencia, hasta que los directivos españoles no logran ganar la confianza de los expatriados chinos no pueden entrar en su círculo más próximo y desarrollar los lazos de amistad que les permitirán el buen entendimiento y la integración cultural. Para lograrlo, los directivos locales prestan especial atención en implicar emocionalmente (ganqing) a los directivos chinos con la filial española organizando regularmente actividades sociales. Por ejemplo, el directivo de Huayi señala que: "largas comidas, brindis de amistad y partidos de fútbol entre los españoles y chinos tienen lugar habitualmente. Dado que los gerentes chinos están muy lejos de su país, sienten la necesidad de hacer amigos aquí".

En consecuencia, gracias a los esfuerzos de los directivos locales y de sus intentos para implantar las prácticas de guanxi se alcanza la aproximación de culturas y la adaptación mutua que facilita el entendimiento. Dada la gran distancia de culturas entre China y España, los directivos locales tienen que ser muy cuidadosos adoptando la cultura de su corporación (legitimidad interna) sin descuidar los requerimientos locales (legitimidad externa) si quieren garantizar el éxito de la EMNE en el país de destino. Así, equilibrando ambas culturas se resuelve el conflicto isomórfico y así consiguen alcanzar simultáneamente la legitimidad externa e interna.

\section{Conclusiones}

Los resultados muestran como la práctica del guanxi se extiende más allá de las fronteras de China. A pesar de que los directivos expatriados chinos son conscientes de la gran distancia cultural existente entre Europa y su país, siguen actuando conforme a la filosofía guanxi fuera de China, ya que se trata de valores fuertemente arraigados. Además, no quieren arriesgarse a perder la confianza de la empresa matriz y asegurarse así la promoción interna en el momento de ser repatriados.

Consecuentemente, la adopción y adaptación del guanxi en el entorno local actúa como "pegamento social" (Forsgren, 2013), permitiendo a los directivos de la filial alinearse con la cultura de la matriz al mismo tiempo que ayuda a adaptarse a la cultura local. Así, la filial consigue lograr el equilibrio entre los dos contextos institucionales a través de la adopción y la adaptación del guanxi a los requerimientos locales, logrando con ello la solución del conflicto isomórfico. Los directivos locales actúan como puente reduciendo la distancia cultural, permitiendo el entendimiento y facilitando la transferencia mutua de conocimiento entre la matriz y la filial extranjera. La adaptación del guanxi al contexto de un país desarrollado como España, resulta esencial para conjugar la necesidad de operar globalmente (en concordancia con la cultura de la matriz y alcanzando la legitimidad interna) con la necesidad de actuar localmente (de acuerdo con los valores del país de destino y asegurando la legitimidad externa) (Figura 1). Por tanto, los directivos locales de la filial de la EMNE deben ser conscientes del papel decisivo que juegan en la adaptación de la EMNE y aproximarse a los aspectos culturales del país de origen, haciendo entender a la vez los valores y la cultura del país de acogida. 
Figura 1. La práctica del Guanxi para mitigar el conflicto isomórfico

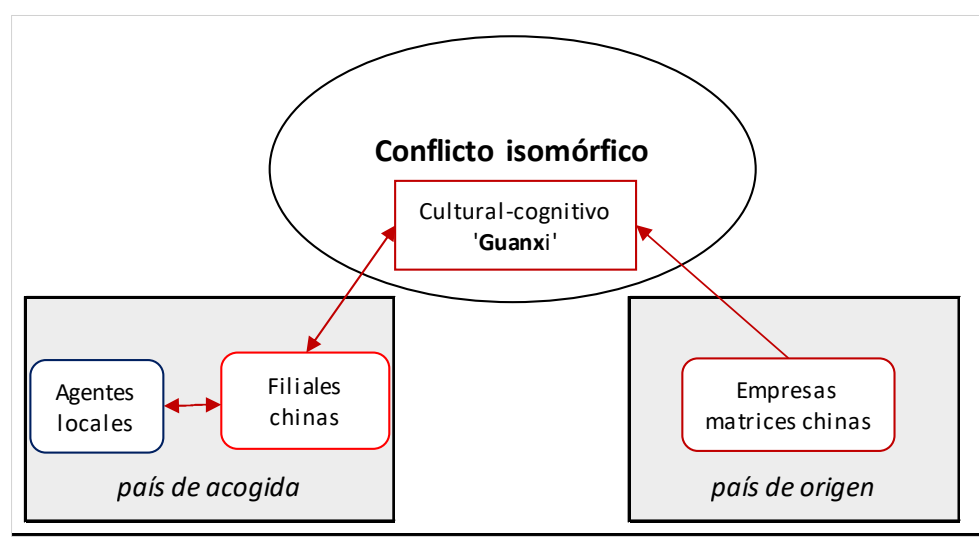

\section{Referencias}

Forsgren, M. (2013). Theories of the multinational firm: A multidimensional creature in the global economy. UK: Edward Elgar Publishing.

Hofstede, G.H. (2001). Cultures consequences: Comparing values, behaviours, institutions and organizations across nations. (2nd ed.). Thousand Oaks, CA: Sage Publications.
Hwang, K. (1987). Face and favor: The Chinese power game. American Journal of Sociology, 92(4), 944-974.

Kipnis, A.B. (1997). Producing guanxi. Durham NC:Duke University Press.

Klossek, A., Linke, B.M., \& Nippa, M. (2012). Chinese enterprises in Germany: Establishment modes and strategies to mitigate the liability of foreignness. Journal of World Business, 47(1), 3544.

Kostova, T., Kendall, R., \& Dacin, T. (2008). Institutional theory in the study of MNCs: a critique and new directions. Academy of Management Review, 33(4), 994-1006.

North, D.C. (1990). Institutions, Institutional Change and Economic Performance. Cambridge: Cambridge University Press.

Scott, W.R. (1995). Institutions and organizations: ideas and interests. USA: Sage.

Wang, Ch.L. (2007). Guanxi vs. relationship marketing, exploring underlying differences. Industrial Marketing Management, 36(1), 81-86. 